\title{
"So, Obama is a Muslim?": Toward Figurative Spaces and Blends in US Same-Sex Marriage Discourse
}

\author{
PONGBODIN AMARINTHNUKROWH \\ Department of Linguistics, \\ Chulalongkorn University, Thailand \\ pongbodin.a@outlook.com
}

\begin{abstract}
This article investigates the meaning construction processes of novel figurative expressions found in the discourse on the US legalisation of same-sex marriage. It is argued that mental spaces theory and conceptual blending theory (MSCB) can be of great analytical benefits when dealing with this type of data. Four cases of novel figurative spaces and blends, namely the Divided Self construal, the Generic is Specific construal, the single-scope blending, and the megablending, are examined to shed light on how same-sex marriage controversies are conceptualised by means of the viewpointed nature of figurative language. In addition, based on the analyses of the four selected cases, this article ends with a discussion on why MSCB is an appropriate choice for examining novel figurative expressions in discourse.
\end{abstract}

Keywords: figurative language; mental spaces; conceptual blending; meaning construction; same-sex marriage

\section{INTRODUCTION}

The public debate over marriages for people of the same sex emerged in the 1980s. However, it was not until June 26, 2015 that the US Supreme Court pronounced same-sex marriage to be legal nationwide. Although this landmark ruling can be regarded as one of the most important social movements of our generation, it is also highly controversial in several aspects - especially in the facets of politics, culture, and religion. In light of this, the debate over same-sex marriage is therefore a brilliant issue to be examined through the lens of figurative language since figurative language is essentially viewpointed. Dancygier \& Sweetser (2014, p. 10) point out that "as figurative language is shaping cognitive construals in discourse, it is typically shaping viewpoint on the relevant content as well". Consider Barack Obama's tweet on the day of the legalisation in (1) to see how figurative language can be used to create the viewpointed reality of ongoing discourse.

(1) Today is a big step in our march toward equality. Gay and lesbian couples now have the right to marry, just like anyone else. \#LoveWins (3387828)

At first glance, some might look at the underlined expressions in (1) and protest, saying "How are they figurative?" "Are they not normal, ordinary ways of talking?" It should be emphasised, in fact, that we have to separate the parameter of everyday usage (or conventionality) from the distinction between literal and figurative. Just because they are conventionally used, it does not necessarily mean they are literal. Let us consider how these conventional expressions are figurative and viewpointed. The first figurative construal involved is the Location Event Structure Metaphor (Location ESM), which conceptualises an abstract event as directed motion along the path. The Location ESM is a broad schema which has sub-structures to be profiled. Specifically, in (1), PROGRESS IS FORWARD MOTION (as in "a big step" and "march"), PURPOSIVE ACTION IS GOAL-DIRECTED MOTION ("march toward"), and STATES ARE LOCATION ("toward equality") are the sub-structures profiled from the Location ESM schema. With these construals, equality is thus viewpointedly conceptualised as a 
physical location where we can enter or move toward, and calling for marriage equality becomes a long and arduous journey. Another figurative construal concerned is objectification. The right to marry is reified as an object that one can possess ("have the right to marry"). Lastly, the hashtag "\#LoveWins" is construed by means of the ARGUMENT IS WAR/COMBAT pattern to describe the process of arguing (in politics to be more specific) beyond simply saying "X says something and then $\mathrm{Y}$ disagrees". By reframing the participants in a political debate as a winner or a loser, a more antagonistic viewpoint toward arguing is achieved.

So far, we have seen viewpoint phenomena at the level of conventional figurative language. At this level, the majority of cognitive discourse analysts tend to employ conceptual metaphor theory (hereafter CMT) ${ }^{2}$ to explain how the topic of the discourse in question is non-neutrally and viewpointedly conceptualised. My analyses of the figurative expressions in (1) above exemplify this approach. However, it should be noted that viewpoint phenomena in figurative language can happen at every level from the most mundane language use (like in (1)) to the wildest and most creative linguistic innovation as in the headline of the news on Obama's position on same-sex marriage below.

\section{(2) Bryan Fischer accuses Obama of being a Muslim for supporting gay marriage (2979393)}

Is Obama a Muslim? This is possibly many people's reaction to this headline. Superficially, it might sound ironic or even meaningless because in reality Obama is, needless to say, not a Muslim and Islam does not by any means support gay marriage. Beyond its literal interpretation, however, we can decipher its figurative meaning along with the ideological messages hidden. I will provide my detailed analysis of the conceptualisation of Obama as a Muslim in SO, OBAMA IS A MUSLIM section, but at this point there is one important theoretical issue that should be raised: Can CMT account for this data? The type of metaphor which CMT focuses on is conventional metaphor that is neurally-wired in our mental lexicon. In this regard, using CMT here implies that OBAMA IS A MUSLIM is an entrenched, conventional metaphorical pattern in our conceptual system. But that should not be the case. Even more importantly, CMT - as suggested by its name - is concerned simply with metaphorical construals and leaves no room for other figurative construals. Therefore, using CMT here inevitably leads to a debate over whether the conceptualization of Obama as a Muslim is a metaphor. And that is a more complex issue than one might think. All these problems together, in my view, explain why novel figurative expressions in discourse have received little attention in cognitive discourse analysis literature. Thus, ideally, this article aims to make some changes to the way people tackle figurative meanings in discourse. I will analyse novel figurative expressions in the discourse on the US legalisation of same-sex marriage to show why these data should not be neglected. Also, I argue that investigating this type of figurative expressions can provide in-depth insight into how the same-sex marriage controversy is conceptualised.

However, this research objective also leads to another critical issue: If CMT is not a suitable choice, then how can we analyse novel figurative expressions such as the Obama being a Muslim in (2)? One way to perform such a task is to rely on mental spaces theory ${ }^{3}$ (Fauconnier, 1994) and its extension known as conceptual blending theory or conceptual integration network ${ }^{4}$ (Fauconnier \& Turner, 2002). Both mental spaces and conceptual blending (henceforth MSCB) assume that "meaning is not a set of discrete conceptual packets neatly correlated with linguistic forms, especially lexical forms, but that in each case it emerges as a result of one's use of formal signals (verbal or not)" (Dancygier, 2012, p. 5). In other words, MSCB can be regarded as a process of online meaning construction which uses 
available aspects of meaning evoked by the signals to yield an interpretation that optimally fits the overall shape and texture of ongoing discourse.

Before I move on to present my MSCB-based analyses of the novel figurative expressions in my discourse data, I would like to emphasise that I by no means imply that MSCB is superior to CMT. Unlike Hart (2008) who argues that blending theory has better analytical benefits than CMT, I believe, as Dancygier (2016) suggests, that both MSCB and CMT have their own analytical strengths, but MSCB is more of "a natural choice when a creative term is used to encapsulate a rich and complex combination of meanings for the purposes of current expression" (p. 35). Nonetheless, only few scholars (see for example Oakley \& Coulson, 2008) have employed MSCB to analyse figurative language in discourse to prove Dancygier (2016)'s claim on the compatibility between MSCB and novel figurative expressions. This leads to the other goal of this study. After I analyse the novel figurative expressions in my data, I will use my analyses to discuss why MSCB is an appropriate choice for examining novel figurative expressions in discourse. Putting all these together, this article is structured in the following way. In the next section, I outline the data of this study, the corpus tools and techniques utilised, and the procedure for identifying figurative expressions. Then, I move on to present my case-by-case analysis of the novel figurative expressions found in increasing order arranged in terms of conceptual complexity ${ }^{5}$. In the last section, I offer a summary and a discussion on the compatibility between MSCB and novel figurative expressions in discourse.

\section{DATA AND METHODS}

The data used in this study is based on the US legalisation of same-sex marriage (US-LSM) corpus. The US-LSM corpus is a 197,385-word specialised corpus extracted from the News on the Web (NOW) corpus (Davies, 2013) ${ }^{6}$ which contains around 6.5 billion words of texts from online newspapers and magazines in 20 different English-speaking countries ${ }^{7}$ from 2010 to the current time. As the US Supreme Court ruled that same-sex marriage was legal nationwide on June 26, 2015, the US-LSM corpus therefore contains only the articles published in 2015. To find figurative expressions, the observed corpus was uploaded to the Wmatrix tool (Rayson, 2008), so that it could be annotated at the semantic level with the USAS semantic tagger (Wilson \& Thomas, 1997). Subsequently, the annotated corpus was compared to the BNC Sampler Written Informative corpus (745,726 words) with the loglikelihood (LL) cut-off point of 15.13 for 99.99 per cent of significance (or $p<0.0001$; 1 d.f.) to find the statistically significant semantic domains belonging to the observed corpus.

In search of metaphorical expressions, I exported the concordance lines of each significant domain and analysed them based on the Pragglejaz (2007)'s Metaphor Identification Procedure (MIP). The procedure reads as follows:

1. Read the entire text to establish an overall understanding

2. Determine the unit of analysis

3. For each unit of analysis, establish its contextual meaning and then consider if it has a more basic meaning which is more concrete, related to bodily action, and historically older

4. If the contextual meaning contrasts with the basic meaning but can be understood in comparison with it, mark that unit of analysis as metaphorical.

For other construals such as figurative spaces and blends, unfortunately, there is no explicit and systematic identification procedure at present. This is not surprising because figurative spaces and blends are normally constructed online as discourse unfolds. In consequence, their patterns and structures are often unpredictable and seem to vary considerably. Therefore, the novel figurative spaces and blends presented in this study were 
found when I went through the concordance lines of each significant domain to identify metaphorical expressions. However, this is not to say that there is no criterion at all. Lakoff \& Turner (1989, p. 67) propose the topology of novel metaphor in poetry, saying "poetic thought uses the mechanisms of everyday thoughts, but it extends them, elaborates them, and combines them in ways that go beyond the ordinary". In other words, to construct novel metaphor, poets can creatively exploit conventional metaphor by using three main ways: extension, elaboration, and combination. It is true that this topology is proposed to capture how novel metaphor in poetry is constructed. Nevertheless, I found that it can be applied to account for other novel figurative construals and to analyse figurative language in other genres as well. To this end, I identified the novel figurative expressions constructed according to this topology by tracing their conventional roots and determining how these roots are exploited to construct novel meanings. The construals presented in THE “UNSHACKLED" PRISONER and THE CRUCIBLE sections are examples of the novel figurative language identified using these criteria.

Crucially, not all novel figurative expressions involve a departure from conventional roots (such as the conceptualisation of Obama as a Muslim). Rather, their novelty lies in the linguistic (or textual) dimension. In light of this, to regard these expressions as novel figurative expressions, I consulted dictionaries and large electronic corpora to determine whether the contextual meaning of the figurative expression in question is novel. If the contextual figurative meaning of the expression deviates from the conventional figurative meaning (which is the most frequent one in reference corpora), or if the contextual meaning of the expression in question is figurative but that expression does not have any figurative senses in reference corpora, then that figurative sense is considered novel at the textual level. The expressions in HOMOSEXUALITY IS A SIN and SO, OBAMA IS A MUSLIM sections were marked by using these criteria.

\section{THE “UNSHACKLED” PRISONER}

Now, let us analyse our first novel figurative expression in the US-LSM corpus. After the legalisation of same-sex marriage, the same-sex marriage controversy is nonetheless far from over. One of the most famous issues after the legalisation is Kim Davis's refusal to comply with Obergefell v. Hodges. Davis refused to issue marriage licenses to same-sex couples due to her religious belief that same-sex marriage is against God's will. As a result of her refusal, Davis was jailed for contempt of court. This incarceration gained international attention as some Christian conservatives believed that Davis's imprisonment was in contradiction to religious liberty. Accordingly, a number of people came out to support Kim Davis, and sentence (3) is a vivid example.

(3) Kim Davis is being treated as a criminal because she cannot violate her conscience. While she may remain behind bars for now, Kim Davis is a free woman. Her conscience remains unshackled. (3563241)

In (3), it appears that Kim Davis's physical body and conscience are conceptualised as two different entities. An important question is: How do we conceptualise one human being as two separate people? One way to address this question is to refer to personification - the process of reframing the ontological status of an abstraction. Viewed in this light, we can say that Davis's conscience is reframed as a person, and this "person" is the one who is confined to the cell. Nevertheless, with MSCB we can take this conventional figurative construal even further and offer a fine-grained explanation of the phenomenon in question. 
In reality, it is impossible for a human being to split or be split into two entities. In addition, it is contradictory to our real-world knowledge to say that someone is a free person when they are imprisoned. Thus, in the context of (3), we have two knowledge structures that interact. On the one hand, we have our real-world knowledge which is contained in the Reality space or the Base space. On the other hand, we have some sets of knowledge which are in direct contradiction to our real-world knowledge in the Hypothetical space which is constructed online in this discourse situation. In the Hypothetical space, Kim Davis is construed by the Divided Self metaphor which allows us to split the Subject, the locus of subjectivity, rationality, and consciousness, from the Self, our bodies, emotions, and part of us that acts in the world (Lakoff, 1996, pp. 98-103). The conceptualisation of the Hypothetical space and the Divided Self in (3) can be partly represented as in Figure 1.

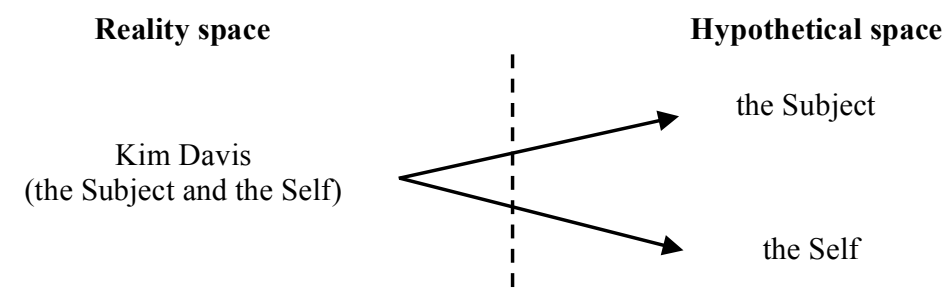

FIGURE 1. The Divided Self construal of Kim Davis

With the Divided Self construal in the Hypothetical space, we can now account for the figurative expressions in (3) and easily decipher the ideological messages hidden behind them. In this discourse situation, it is simply the Self, or Davis's body, that is behind bars. Her conscience, or Subject, however remains "unshackled". Crucially, the unshackled Subject is viewpointed. Since Davis is a Christian conservative who used her religious beliefs as a justification for her action, it can be assumed that "her conscience" refers to her awareness of Christian ideology that homosexuality and same-sex marriage are sinful. In this regard, her conscience is viewpointed with this Christian ideology and thus becomes a figurative "person" who is more righteous than the supporters of same-sex marriage. Furthermore, with this viewpoint phenomenon in the Divided Self construal, the textproducer can convey at least two more ideological messages. First is that no matter what the supporters of same-sex marriage do to Davis and other Christians, they will always hold on to God's teachings because it is the righteous path that they cannot "violate". The other potential ideological message is concerned with how the supporters of same-sex marriage are indirectly portrayed. As a result of Davis's viewpointed conscience, the supporters of samesex marriage and those who imprisoned her thus become the villains in this context.

In this section, we have seen how figurative expressions can create viewpoints as discourse develops. Personification which is a stepping-stone to the conceptualisation of more complex and creative expressions is viewpointedly elaborated to suit the textproducer's communicative intent. More importantly, we have also seen that, unlike other frameworks, MSCB allows us to include the discourse context in the overall meaning construction process. Due to this analytical strength, MSCB thus becomes an appropriate choice for discussing how creative and new meanings are added to the conventional ways of talking in ongoing discourse as in the case of Davis - the "unshackled" prisoner.

\section{HOMOSEXUALITY IS A SIN}

"Homosexuality is a sin", "Homosexual acts are evil", "Marriage is a sacrament", and so on. These are examples of the Generic is Specific construal found in my corpus data. Originally, 
this construal is claimed to be a metaphor that "maps a single specific-schema onto an indefinitely large number of parallel specific-level schemas that all have the same genericlevel structure as the source-domain schema" (Lakoff \& Turner, 1989, p. 162). However, it is quite debatable whether the Generic is Specific is a metaphor (see McGlone, 2007 and Sperber \& Wilson, 2008). Still, whether the Generic is Specific construal is metaphorical or not, it is surely non-literal and can reflect some interesting ideological aspects. Viewed in this light, I will not continue with the debate over the matter of categorisation and try to confine this construal to any artificially invented categories. Rather, I will analyse this construal in a particular discourse context to shed light on its structure and meaning. Similar to Sullivan and Sweetser (2009), I argue that MSCB has the explanatory power to offer insight into the meaning of the Generic is Specific construal. To see how MSCB can do such a task, consider the underlined expression in (4).

(4) The majority opinion acknowledged the rights of those who disapprove of same-sex marriage to continue to believe that homosexuality is a sin. (3393116)

In (4), "homosexuality is a sin" is where we can find the Generic is Specific construal. Before I present my analysis, it should be noted that this construal occurs in the Belief Hypothetical space constructed as a result of the word "believe" which is a space builder - an expression that "may establish a new space or refer back to one already introduced in the discourse" (Fauconnier, 1994, p. 17). Since this construal resides in the Belief Hypothetical space, it suggests that the meaning of the Generic is Specific construal is not based on the reality, but on the mentality of the believer or "those who disapprove of same-sex marriage".

Returning to the Generic is Specific construal in (4), it is obvious that we are now facing an interaction of two concepts: Homosexuality and Sin. However, it is very unlikely to say that Homosexuality here is metaphorically conceptualised in terms of Sin. What can be seen instead is an evocation of a concept's non-prototypical frame which occurs when that concept is juxtaposed with a prototypical member of the very same frame. Although, the concept Homosexuality by itself concerns the Religion frame, it is simply a peripheral member of the Religion frame in prototype theory (see for example Rosch, 1975; 1977). In other words, we can say that the Religion frame is a non-prototypical frame of the concept Homosexuality. In the discourse context of (4), the text-producer aims to evoke this nonprototypical frame in order to evoke as well the religious viewpoints toward Homosexuality. Therefore, the concept Sin which is a prototypical member of something wicked and immoral in the Religion frame is used to help evoke the Religion frame in the Homosexuality concept and transfer the negative viewpoint to it. This meaning construction process can be briefly illustrated as in Figure 2. Note that the blend in Figure 2 maps the viewpoint from Sin to Homosexuality (as indicated by the arrow). This mapping is, in my view, not a metaphorical mapping but a transfer of viewpoints from a paragon prototype in the category of something immoral to a non-prototypical member in the same category. Viewed in this light, the concept Homosexuality is therefore ideological and viewpointed as something extremely negative and immoral in a religious manner.

In this section, I have shown that, with MSCB, we can leave aside the debate over whether the Generic is Specific construal in (4) counts as a metaphor, and offer instead a detailed understanding of its meaning construction process. Even more importantly, based on the meaning construction process of the Generic is Specific construal, we can redefine Lakoff \& Turner's definition and view this type of construal as a blend that "maps the family resemblances characterising a category prototype to other category members" (Sullivan \& Sweetser 2009, p. 309). 


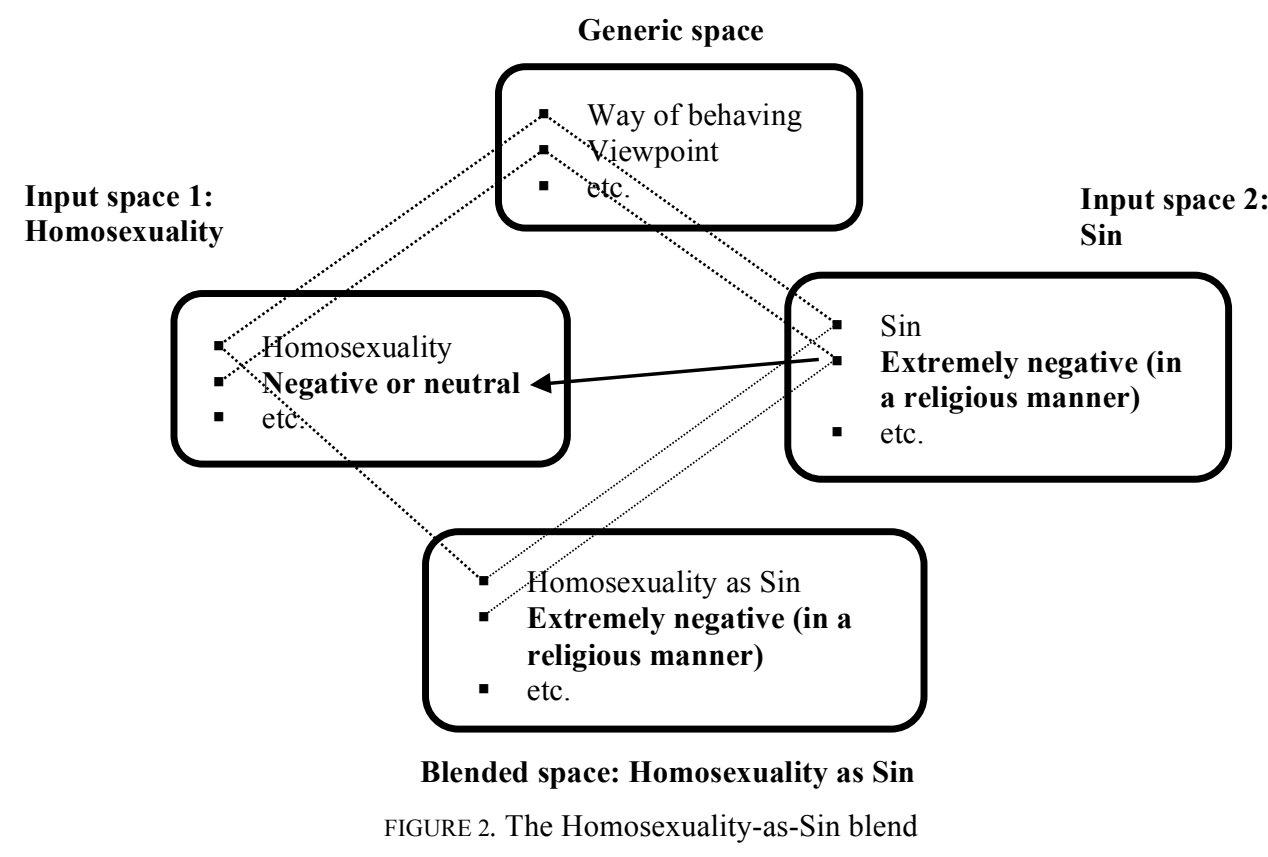

\section{THE CRUCIBLE}

San Francisco is known as "the gay capital of America" or "the gay Mecca" due to its gay nightlife, culture, and politics. It also has a long history of LGBTQ rights and activism. More importantly, in 2004 San Francisco Mayor Gavin Newsom defied the law of California by issuing marriage licenses to same-sex couples. In response to this defiance, President George W. Bush announced support for a federal constitutional amendment banning same-sex marriage. Eventually, San Francisco could not resist the tension and had to stop issuing marriage licenses to same-sex couples in accordance with the CA Supreme Court's ruling. In this regard, San Francisco can also be metaphorically referred to as "a crucible of the gay rights movement" as in sentence (5).

(5) Around a million people were expected in San Francisco, a crucible of the gay rights movement, following equally ebullient Pride marches in London, New York, Dublin, Paris and other cities. (3390141)

The word "crucible" literally means "a container used for heating substances or melting metals at very high temperatures" (Macmillan Dictionary Online 2018). However, it can also be used figuratively in the context of (5) as a place or situation in which people or ideas are tested severely. But how can we decipher the meaning construction processes of this figurative sense? From the historical background, we can see that there was a political conflict between San Francisco and the CA Supreme Court on the idea of issuing marriage licenses to same-sex couples. And this Conflict is metaphorically construed as Heat (in a crucible). In other words, the figurative expression in (5) is a linguistic realisation of the CONFLICT IS HEAT/FIRE conceptual metaphor, and the mappings of this conceptual metaphor can be shown as in Table 1. Note that the CONFLICT IS HEAT/FIRE metaphor is also based on the LEVEL OF TEMPERATURE FOR INTENSITY OF EMOTION metonymy since there is a correlation in experience between hostile emotions in conflicts and high temperature. 
TABLE 1. Mappings for CONFLICTS IS HEAT/FIRE

\begin{tabular}{ccc}
\hline Conflict (Target) & & Heat/Fire (Source) \\
\hline the entity involved in the conflict & $\leftarrow$ & the thing burning \\
the conflict & $\leftarrow$ & the fire \\
the intensity of conflict & $\leftarrow$ & the intensity of heat \\
the cause of the conflict & $\leftarrow$ & the cause of the fire
\end{tabular}

Based on the CONFLICT IS HEAT/FIRE conceptual metaphor and the LEVEL OF TEMPERATURE FOR INTENSITY OF EMOTION conceptual metonymy, the text-producer can conceptualise San Francisco as "a crucible for the gay rights movement" to express the tension and conflicts between San Francisco and the CA Supreme Court. With MSCB, however, we can work at the level of mental spaces and provide more detailed descriptions of this conceptualisation. Prior to providing my MSCB-based analysis of this meaning construction, it should be noted that although MSCB is claimed to be a brilliant apparatus for creative, novel figurative expressions, it does not mean that novel figurative spaces and blends are always truly novel. This is because most of the time we cannot just invent brand new figurative expressions, but rather make use of existing conventional expressions in our language (Lakoff \& Turner, 1989). With this in mind, even if I do not mention the CONFLICT IS HEAT/FIRE conceptual metaphor and the LEVEL OF TEMPERATURE FOR INTENSITY OF EMOTION conceptual metonymy in my MSCB-based analysis of the figurative expression in (5), it should be crystal clear that it is based highly on these conventional roots.

Returning to the conceptualisation of San Francisco as a crucible, here there are two mental spaces involved: the San Francisco space (input 1; the target) and the Crucible space (input 2; the source). The elements from these two inputs are projected onto the blend and fused together. San Francisco becomes a crucible which has its support for the gay rights movement as the substance inside. Also, issuing marriage licenses in defiance of the CA Supreme Court's ruling is viewed as an act of heating the substance inside the Crucible. And since San Francisco was the losing side in the historical context, its support for same-sex marriage is conceptualised as a melting substance accordingly. The conceptualisation processes described above can be illustrated as in Figure 3. By utilising MSCB and looking at the mental space level, we can decipher the text-producer's major communicative intent: Similar to how strong and solid metals are melted in the crucible, San Francisco's firm support for gay rights was criticised and attacked so severely that it had to eventually capitulate to the CA Supreme Court's ruling.

Notably, the San Francisco-as-Crucible blend is an example of the single-scope blend discussed in MSCB literature. The reason why this type of blend is referred to as a singlescope is because only one input (or the source input) contributes to structure of the blend. Specifically, it is the Crucible space that provides the primary organising frame for the blend, and thus determines the basic blend structure. The San Francisco space, however, merely projects its elements onto the blend, so that those elements can be fused with the elements and the frame structure of the Crucible space. 


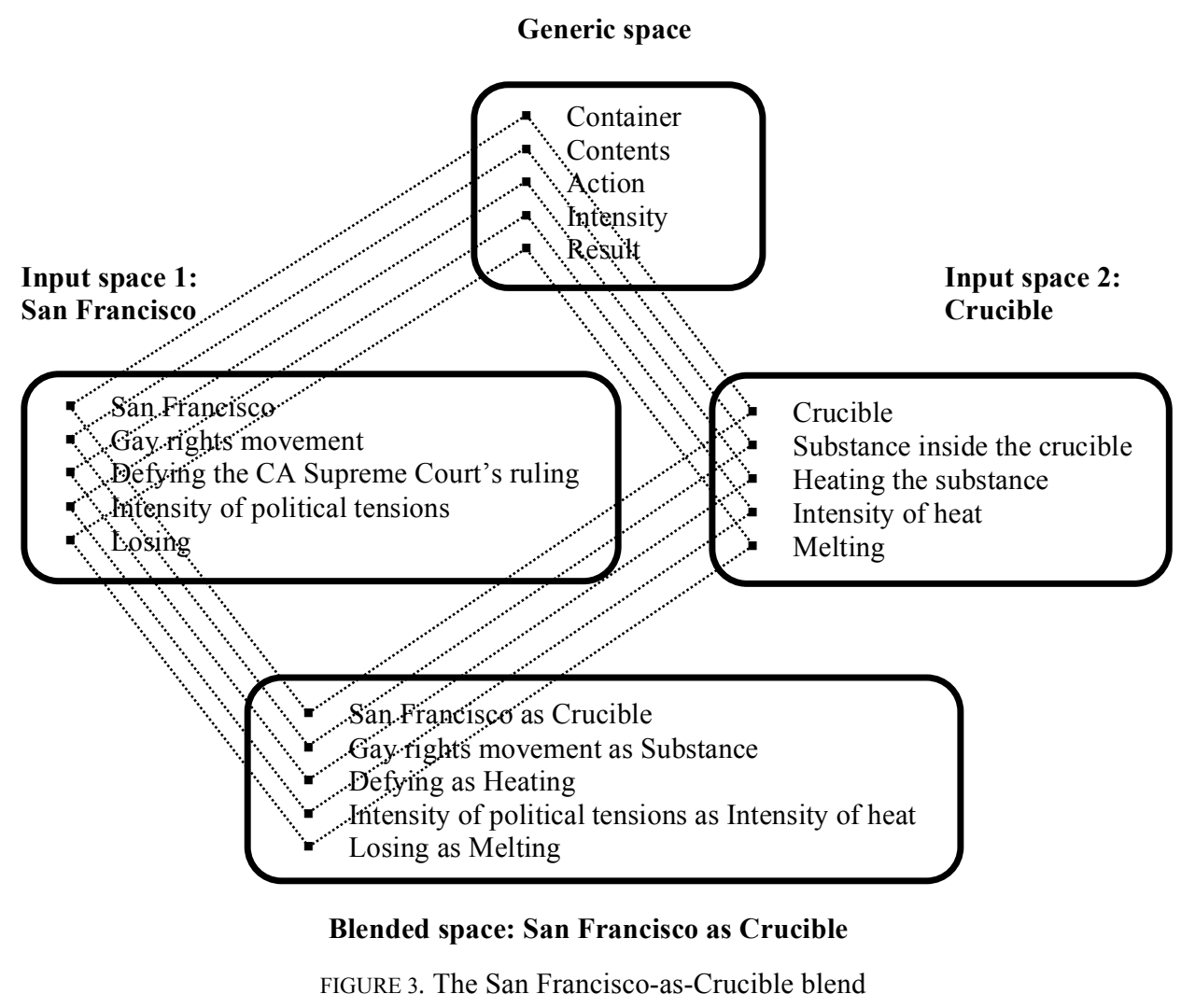

\section{SO, OBAMA IS A MUSLIM?}

Having discussed various types of figurative spaces and blends in the US-LSM corpus, now let us return to the most conceptually complex conceptualisation or the conceptualisation of Obama as a Muslim mentioned in the introductory section. When Barack Obama made his position clear that he was completely in favour of legalising same-sex marriage, Bryan Fischer, the head of American Family Association (AFA), criticised him with bigoted remarks on his radio show on January 16, 2015. Consider (6) to see how Fischer sneered at Obama and his position on legalising same-sex marriage.

(6) Bryan Fischer accuses Obama of being a Muslim for supporting gay marriage... "Nobody can support and promote and celebrate homosexual behaviour who is a sincerely devoted follower of Christ. It's impossible, because Christ and his apostles made it very clear that's a sin". Fischer went further still; suggesting that Obama is actually a follower of Islam. "He walks like a Muslim. He talks like a Muslim. He sounds like a Muslim. He acts like a Muslim." (2979393)

Even a cursory glance at the excerpt above can make the reader stunned by Fischer's irony since Fischer's arguments are in direct contradiction to Islamic ideology. According to the Quran (7, p. 81-84) $)^{8}$, for those who "practise lusts on men instead of women... we rain down on them a rain of stones". In other words, homosexual behaviours are considered a vile form of sexual behaviours; those who practise them must be sentenced to death in accordance with the Sharia, or Islamic law. At this point, one important question must be raised: If Islamic teachings are totally against homosexuality, how can Obama be called a Muslim for supporting same-sex marriage? One possible explanation is that the knowledge structure of the concept Islam is reconceptualised in this discourse context. This explanation in turn leads 
to another question: How can this reconceptualisation be accounted for? Note that the conceptualisation of Obama as a Muslim in (6) does not occur in the Reality space. Rather, it resides in a Hypothetical space evoked by the space builder "accuses". In this regard, the knowledge structure of Islam here must be interpreted based on Fischer's perspective (which is clearly negatively viewpointed), and that is the very first step toward our MSCB-based meaning deciphering procedures.

To reconceptualise the concept Islam, we need two input spaces: the Islam space and the Social Institution Allowing Gay Marriage space. The elements from these inputs project into the blend to construct an emergent blend structure in which gay marriage is not considered sinful or contradictory to Islamic teachings. Crucially, not all elements from both inputs are chosen for projection. Only the element needed for the blend is selected and projected into the blend - and this kind of projection is referred to as selective projection. From the Islam input, the blend selects only one element - i.e. the followers of Islam or Muslims. From the Social Institution Allowing Gay Marriage input, an idea of supporting gay marriage is selected. The selected elements from both inputs are fused together in the blend, yielding an emergent structure being specific to the blend which is Muslims supporting samesex marriage. This blend (or the Islam Supporting Gay Marriage blend) then becomes an input for another blend called a Sinful Muslim blend. To construct the Sinful Muslim blend, another input is required: the Christianity input. Again, only elements needed are projected into the blend. From the Islam Supporting Gay Marriage blend/input, Muslims and the emergent blend element (Islam supporting gay marriage) constructed earlier are selected. From the Christianity space, the element that following Christ is the right and virtuous way of life is chosen. In the blend, these selected elements are combined and result in a figurative emergent meaning, which is Islam or being a Muslim is wrong. This emergent meaning arises as a result of the juxtaposition between two contradictory elements in the blends: supporting gay marriage and following Christ is the right path. Since in this Hypothetical space the way of life that Christ paved for us is considered a moral standard ("Christ and his apostles made it very clear that's a sin"), Islam and Muslims which do not follow Christ and support gay marriage in this context are therefore viewpointed as morally wrong. The blending diagram illustrating the online meaning construction of the Sinful Muslim megablend - a blend consisting of multiple layers - can be partly presented as in Figure 4. Note that the emergent meaning is presented in a box inside the blend, and the generic spaces are omitted to simplify the diagram.

The megablend in Figure $4^{9}$ has not yet covered all shades of the meaning of (6) - we still need another layer of blending network to complete the conceptualisation of Obama as a Muslim or the Obama-as-Muslim blend. To construct this blend, a simplex blend is required. For this type of blend, role-value mappings are the essence as "the relevant part of the frame in one input is projected with its roles, and the elements are projected from the other input as values of those roles within the blend" (Fauconnier \& Turner, 2002, p. 120). In other words, simplex blends profile specific roles from one input and map these roles onto specifics values in the other input. Returning to the construction of the blend in question, the Sinful Muslim megablend constructed earlier now functions as an input providing roles for the blend. These roles are then projected onto specific values - Obama (an individual), Obama's position on gay marriage, and a viewpoint toward Obama - in the other input, or the Obama input. The simplex blend for the construction of the Obama-as-Muslim blend can be illustrated as in Figure 5. Importantly, Figure 5 (or the third layer of our megablend) is where the online meaning construction of Obama as a Muslim is complete. 


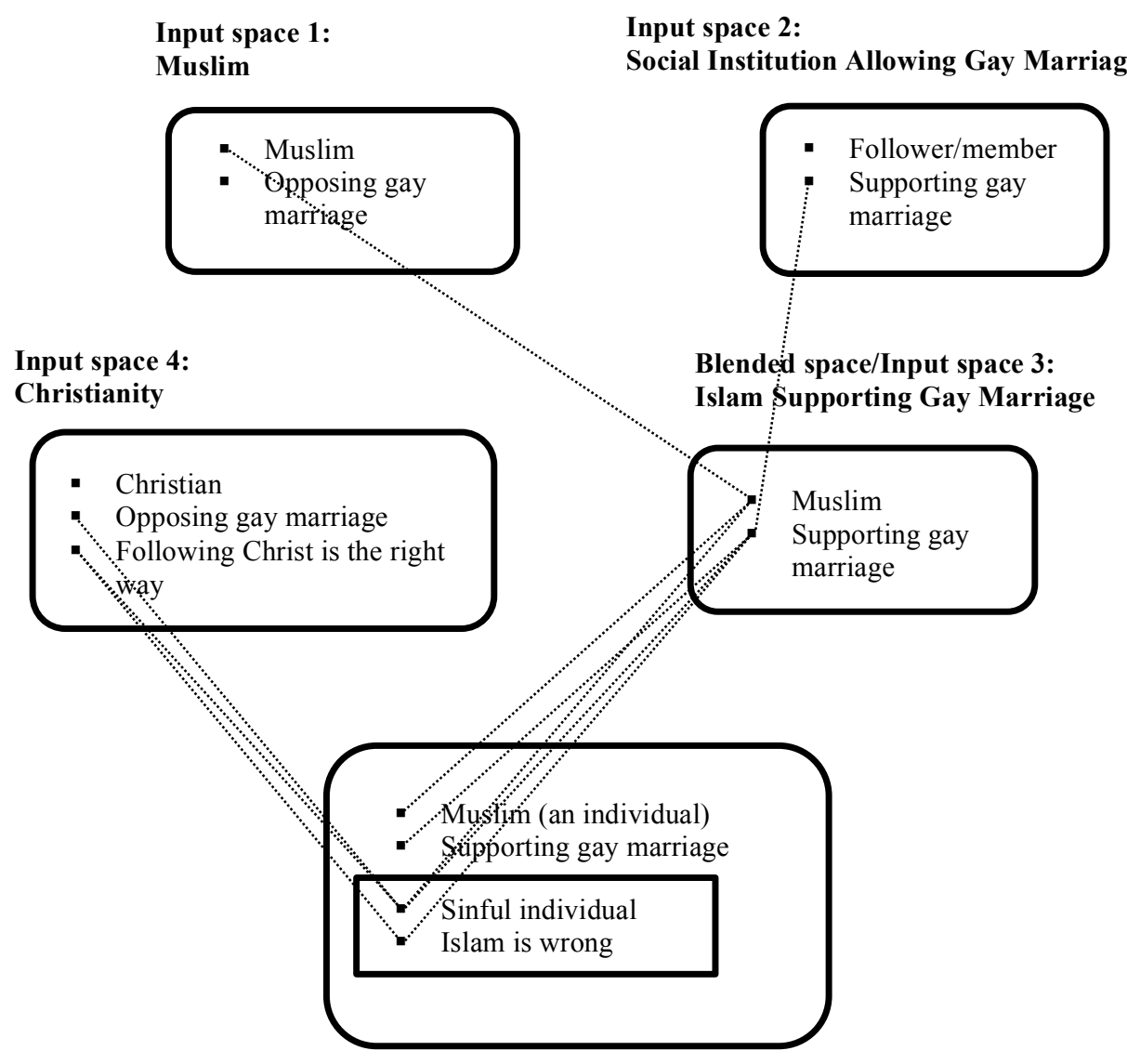

Blended space: Sinful Muslim

FIGURE 4. The Sinful Muslim megablend

Input space 6:

Obama
Blended space/Input space 5: Sinful Muslim

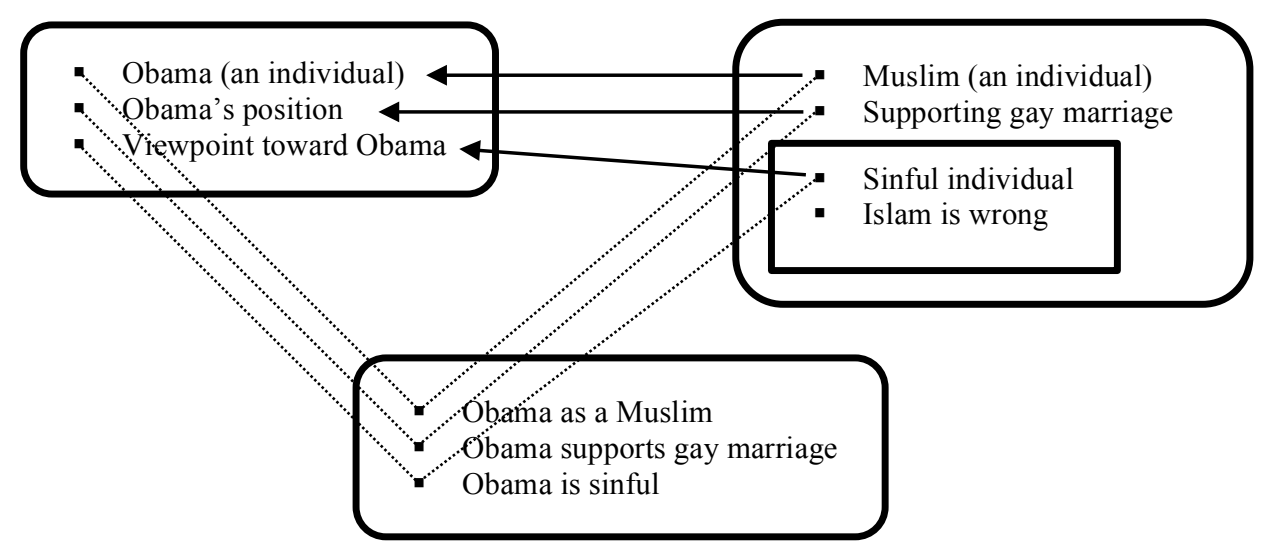

Blended space: Obama as a Muslim

FIGURE 5. The Obama-as-Muslim blend 


\section{CONCLUSION AND DISCUSSION}

Having offered the MSCB-based analyses of four interesting cases of creative, novel figurative expressions in my data, I hope to convince you that MSCB is of great benefit when dealing with novel expressions in discourse. Based on the analyses, we can observe that MSCB-based meaning construction processes are a matter of conceptualisation, or "a dynamic process whereby linguistic units serve as prompts for an array of conceptual operations and the recruitment of background knowledge" (Evans \& Green, 2006, p. 164), as they are not simply concerned with the semantic meanings of the concepts involved, but also depend heavily on our encyclopaedic knowledge and the surrounding discourse contexts ${ }^{10}$. Looking through the lens of discourse analysis, due to its encyclopaedic nature along with its dependence on discourse contexts, MSCB can help us to reach one of the goals of doing discourse analysis, or to uncover and denaturalise what seems to be commonsensical (Fairclough, 2001; Abas \& Kaur, 2019). The Divided Self construal discussed in THE "UNSHACKLED" PRISONER section is a brilliant example of this point. Superficially, the Divided Self construal might seem to be a pure and simple use of figurative language. With MSCB, nevertheless, we can denaturalise this language phenomenon and shed light on how viewpoints come into play in the overall meaning construction process. In other words, we can move away from simply personification and uncover the backgrounded discourse participants, or the supporters of same-sex marriage and those who imprisoned Kim Davis, who are indirectly portrayed as the villains in the context. In this respect, MSCB can not only offer a fine-grained analysis of meaning construction processes of figurative language in discourse, but it can also help to denaturalise hidden meanings and raise some awareness of the ideological, viewpointed nature of the (figurative) language we use.

Illustrating the analytical strengths of MSCB is one thing, discussing why MSCB has those benefits is another. Thus, the rest of this section is dedicated to discuss this matter. Recall Dancygier (2016)'s observation on MSCB and novel figurative expressions mentioned in the introductory section. MSCB is suggested to be "a natural choice when a creative term is used to encapsulate a rich and complex combination of meanings for the purposes of current expression" (Dancygier, 2016, p. 35). But why is MSCB a natural choice in this situation? To shed light on this question, I will apply Kövecses (2017)'s levels of metaphor. In the cognitive approach to figurative language research, the basic-tool is comprised of image schemas, domains, frames, and mental spaces. These four concepts are arranged in order from the most schematic to the least schematic as in Figure 6. While the first three concepts - i.e. image schemas, domains, and frames - belong to our long-term memory, mental spaces function online in our working memory. Importantly, these four concepts are not distinct from one another. Rather, they are linked together and form a unified system of conceptual knowledge. In this light, the use of a mental space in a particular context will activate the frame to which it is linked, and in turn this frame will activate the domain of which the frame is a part, and the domain activation, then, will evoke the schematic structure of image schema. To see a clearer picture, let us consider again the San Francisco-as-Crucible blend. As mentioned in THE CRUCIBLE section, the San Francisco-as-Crucible is concerned with the San Francisco space and the Crucible space. Although these two conceptual structures are constructed online in their discourse context, they are based primarily on other conceptual structures in our long-term memory - i.e. the Heat/Fire frame (and domain) and the Container schema. In this light, by using these two mental spaces in the blending operation, the knowledge structures from these frame, domain, and schema are also activated. 


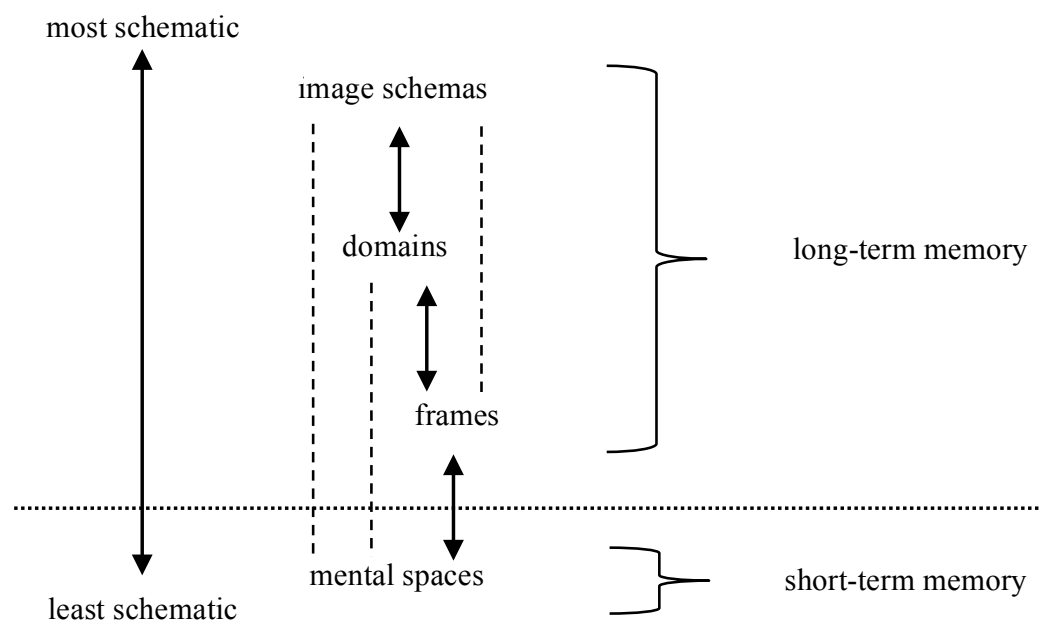

FIGURE 6. The basic tool-kit (Adapted from Kövecses, 2017)

Now let us discuss why MSCB is an appropriate apparatus for studying novel figurative expressions in discourse. Since mental spaces and blends are "constructed as we think and talk, for purposes of local understanding and action" (Fauconnier 2007, p. 351) and belong to our short-term memory, they are therefore dynamic and can be manipulated or modified in ongoing discourse. In other words, it is at this level or the level of mental spaces that we can create novel figurative expressions, perform conceptual blending operations, add viewpoints, modify conceptual structures in long-term memory to suit our communicative intent, and so forth. Note that my analyses of the Divided Self, the Generic is Specific, the San Francisco-as-Crucible blend, and the Obama-as-Muslim megablend have already shown all these operations.

Even more importantly, figurative language in discourse can be more or less conventional as sometimes the text-producer may have to work at the level of short-term memory and create novel expressions to convey some particular messages which cannot be successfully expressed by using conventional figurative patterns entrenched in our long-term memory. Viewed in this light, it seems that both MSCB and novel figurative expressions belong to the very same level of analysis: the level of short-term memory. And since the two work at the same level, they are a match for each other as a consequence.

In sum, this article begins with the MSCB-based analyses of novel figurative expressions found in the US-LSM corpus. It has been argued throughout the paper that MSCB is a suitable choice for analysing novel figurative expressions in discourse. Also, by looking at different levels of schematicity and working memory, we discuss why MSCB suits this type of data better - both of them belong to the same level of analysis.

\section{ACKNOWLEDGEMENTS}

This research owes the most to my Thesis committee: Naruadol Chancharu, Pavadee Saisuwan, Raksangob Wijitsopon, and Kachen Tansiri. Special thanks go to Shane Avery for his support and constructive comments.

\section{ENDNOTES}

1. This article is part of an MA Thesis titled "Metaphors in U.S. Same-Sex Marriage Discourse: A Corpus-Based Study".

2. CMT is a research enterprise aiming to explain how our patterns of thought are metaphorical in nature. To this end, CMT practitioners use systematic sets of metaphorical expressions (or linguistic metaphors) as bases for postulating the existence of conceptual metaphors. For instance, we know that the ARGUMENT IS WAR/COMBAT conceptual metaphor exists because we can find a body of expressions derived from this metaphorical pattern - e.g. "Your claims are indefensible", "He attacked every weak point in my argument", "He shot down all of my arguments", and so on (Lakoff \& Johnson 1980, p. 48). 


\section{L: The Southeast Asian Journal of English Language Studies - Vol 25(4): 1 - 15 \\ http://doi.org/10.17576/3L-2019-2504-01}

3. Mental spaces theory is originally introduced to account for referential opacity such as "In Len's painting, the girl with blue eyes has green eyes" (Fauconnier 1994, p. 12). The mental spaces analysis allows us to have more than one space in one particular construal. So, in this case we have the Reality space and the Picture space. The cross-mapping operation then links the actual girl in the Reality space with the attribute of having green eyes in the Picture space and results in the same referent having different eye colours at the same time. With this strength, mental spaces theory can therefore be applied to help explain a number of figurative construals such as the Divided Self (Lakoff, 1996), metaphorical counterfactuals, and so forth.

4. Conceptual blending theory is by large a theory for online meaning construction. It accounts for various conceptual operations during discourse, figurative language included. The essential claim of blending theory is that conceptual packets (here called input spaces) can be activated and integrated into a new conceptual configuration (called a blend) as discourse develops. The blend, though relying primarily on the inputs, can also have its own uniqueness (or emergent structure) constructed by selecting the relevant parts from the inputs and compressing them to yield new meanings. A classic example of blending is the Buddhist monk riddle which asks: Suppose that a monk walks up a mountain at dawn one day, reaches the top at sunset, meditates at the top for several days until one dawn when he begins to walk back and reaches the foot of the mountain at sunset, with no assumptions about his stopping or about his pace, is there a place on the path that the monk meets himself at the same hour of the day on the two separate journeys? Fauconnier \& Turner (2002, pp. 39-44) answer this riddle using blending theory. In this scenario, two input spaces - the Upward Journey space and the Downward Journey space - project their elements into the blend. The mountain slopes, moving individuals, and the moving directions from both inputs are compressed and fused together to form a unified emergent structure of two people walking on a path in opposite directions and eventually encountering each other.

5. Conceptual complexity is the term I coined to capture the arrangement of the operations in MSCB literature. The degree of conceptual complexity can be arranged from the least complex to the most complex as follows: mental spaces operations, simplex blending, mirror blending, limited-scope blending, single-scope blending, double-scope blending, and megablending. Note that this hierarchy is based purely on how complex it is to perform and explain these artificially invented operations, not on any experimental evidence.

6. For further information and online use of the NOW corpus, see https://corpus.byu.edu/now/

7. Those 20 countries are the United States of America, Canada, the Great Britain, India, Australia, Ireland, South Africa, Nigeria, New Zealand, Singapore, Malaysia, the Philippines, Pakistan, Ghana, Kenya, Sri Lanka, Jamaica, Bangladesh, Hong Kong, and Tanzania.

8. Based on the English translation of the Noble Quran by Dr. Muhammad Taqi-ud-Din Al-Hilali, Ph.D. and Dr. Muhammad Muhsin Khan. Available online at: https://www.noblequran.com/translation/

9. Apart from being an illustrative example of megablends, the Sinful Muslim blend also exemplifies another type of blend - a double-scope blend. The double-scope blend is a blend where two "inputs with different (and often clashing) organising frames...make central contributions to the blend" (Fauconnier \& Turner 2002, p. 131). In addition, "unlike a single-scope blend, [none of the inputs] is reconstrued in terms of the other" (Dancygier \& Sweetser 2014, p. 94). Viewed in this light, metaphorical expressions generated by double-scope blends are not in the TARGET IS SOURCE metaphorical pattern. Rather, their organising structures are based on a fusion of two different inputs.

10. This idea is common in cognitive linguistics which a usage-based approach to language aiming to study how language can reflect and reveal the human mind (Evans \& Green, 2006; Hung, 2019).

\section{REFERENCES}

Abas, N. \& Kaur, S. (2019). Theologising the discourse of representation through 'faith' and religion in football news. 3L: The Southeast Asian Journal of English Language Studies. Vol. 25(3), 150 - 162.

Dancygier, B. (2012). The Language of Stories: A Cognitive Approach. Cambridge: Cambridge University Press.

Dancygier, B. (2016). Figurativeness, conceptual metaphor, and blending. In E. Semino \& Z. Demjén (Eds.). The Routledge Handbook of Metaphor and Language (pp. 28-41). Abingdon: Routledge.

Dancygier, B. \& Sweetser, E. (2014). Figurative Language. Cambridge: Cambridge University Press.

Davis, M. (2013). Corpus of news on the web (NOW): 3+ billion words from 20 countries, updated every day. Available at https://corpus.byu.edu/now/.

Evans, V. \& Green, M. (2006). Cognitive linguistics: An introduction. Edinburgh: Edinburgh University Press.

Fairclough, N. (2001). Language and Power. $\left(2^{\text {nd }}\right.$ ed.). England: Pearson Education Limited.

Fauconnier, G. (1994). Mental Spaces: Aspects of Meaning Construction in Natural Language. Cambridge: Cambridge University Press.

Fauconnier, G. (2007). Mental spaces. In D. Geeraerts \& H. Cuyckens (Eds.). The Oxford Handbook of Cognitive Linguistics (pp. 371-376). Oxford: Oxford University Press.

Fauconnier, G. \& Turner, M. (2002). The Way We Think: Conceptual Blending and the Mind's Hidden Complexities. New York: Basic Books.

Hung, B. P. (2019) A cognitive linguistic approach to teaching English idioms to EFL students: Experimental results. 3L: The Southeast Asian Journal of English Language Studies. Vol. 25(2), 113 - 126.

Kövecses, Z. (2017). Levels of metaphor. Cognitive Linguistics. Vol. 28(2), 321-347. 
Lakoff, G. (1996). Sorry, I'm not myself today: The metaphor system for conceptualizing the self. In G. Fauconnier \& Sweetser, E. (Eds.). Spaces, Worlds, and Grammar (pp. 91-123). Chicago: University of Chicago Press.

Lakoff, G. \& Johnson, M. (1980). Metaphors We Live by. Chicago: University of Chicago Press.

Lakoff, G. \& Turner, M. (1989). More Than Cool Reason: A Field Guide to Poetic Metaphor. Chicago and London: The University of Chicago Press.

MacMillan Dictionary Online [online]. Available at: https:/www.macmillandictionary.com. [Accessed December 28, 2018].

McGlone, M. (2007). What is the explanatory value of a conceptual metaphor?. Language and Communication. Vol. 27, 109-126.

Oakley, T \& Coulson, S. (2008). Connecting the dots: Mental spaces and metaphoric language in discourse. In Oakley, T \& Hougaard, A. (Eds.) Mental spaces in discourse and interaction (pp. 27-50). Amsterdam: John Benjamins Publishing.

Pragglejaz Group 2007. MIP: A method for identifying metaphorically used words in discourse. Metaphor and Symbol. Vol. 22(1), 1-39.

Rayson, P (2008). From key words to key semantic domains. International Journal of Corpus Linguistics. Vol. 13(4), 519-549.

Rosch, E. (1975). Cognitive representations of semantic categories. Journal of Experimental Psychology: General. Vol. 104, 192-233.

Rosch, E. (1977). Human categorization. In N. Warren (Ed.). Studies in Cross-linguistic Psychology (pp. 1-49). London: Academic Press.

Sperber, D. \& Wilson, D. (2008). A deflationary account of metaphor. In R. Gibbs (Ed.). The Cambridge Handbook of Metaphor and Thought (pp. 84-108). Cambridge: Cambridge University Press.

Sullivan, K. \& Sweetser, E. (2009). Is "generic is specific" a metaphor?. In F. Parrill, V. Tobin \& M. Turner (Eds.). Meaning, Form, and Body (pp. 309-328). Stanford: CSLI Publications, 309-328.

Wilson, A. \& Thomas, J. (1997). Semantic annotation. In R. Garside, G. Leech, \& A. McEnery (Eds.). Corpus Annotation: Linguistic Information from Computer Texts (pp. 55-65). London: Longman. 